\title{
NANOKRISTAL TEKNOLOJISI: ÇÖZÜNÜRLÜĞÜ DÜşÜK ILAÇLARIN ORAL BIYOYARARLANIMIN ARTIRILMASI
}

\section{NANOCRYSTAL TECHNOLOGY: INCREASING ORAL BIOAVAILABILITY OF LOW-SOLUBLE DRUGS}

\author{
Yağmur Pirinçci TOK ${ }^{1}$ (D) Sevgi GÜNGÖR ${ }^{1}$ (D), Yıldız ÖZSOY ${ }^{1}$ (D) \\ 1'stanbul Üniversitesi, Eczacılık Fakültesi, Farmasötik Teknoloji Ana Bilim Dalı, İstanbul, Türkiye \\ ORCID ID: Y.P.T. 0000-0001-6915-0283; S.G. 0000-0002-8199-3010; Y.Ö. 0000-0002-9110-3704
}

Attf/Citation: Pirincci Tok Y, Gungor S, Ozsoy Y. Nanocrystal technology: increasing oral bioavailability of low-soluble drugs. Sağlık Bilimlerinde Ileri Araştırmalar Dergisi 2022;5(1):62-70. https://doi.org/10.26650/JARHS2021-808337

Öz

Nanokristal teknolojisi partikül boyutu 1000 nanometre $(\mathrm{nm})^{\prime}$ nin altında, herhangi bir taşıyıcı sisteme ihtiyaç duymadan katı ilaç partikülerinin üretilmesini sağlar. Sudaki çözünürlüğü düşük ilaçların partiküllerinin boyutunun küçültülmesi ile, yüzey alanlarının artması ve difüzyon tabakasının kalınlığının azaltılması k çözünürlük hızının da artışına yol açar. Buna bağlı olarak, absorpsiyon bölgesinde artan konsantrasyon gradienti bağırsak lümeni ve kan arasındaki pasif difüzyon yoluyla permeasyonu ve emilimi teşvik etmektedir. Dolayısıyla Biyofarmasötik Sınıflandırma Sistemi (BCS) Sınıf II ve IV'e ait ilaç molekülleri için nanokristal teknolojisi yaklaşımını kullanarak biyoyararlanımlarını geliştirmek ve/veya arttırmak oldukça önemlidir. Nanometre boyutunda ilaç partikülü elde edebilmek için yukarıdan aşağıya (top-down) ve aşağıdan yukarıya (bottom-up) yöntemlerinden yararlanılmaktadır. İlaç endüstrisinde uygulama kolaylı̆̆ı, tekrar edilebilirliği ve ölçeklendirilebilmesi nedeniyle bilyeli değirmende yaş öğütme (BWM) ve yüksek basınçlı homojenizasyon (HPH) olarak alt bölümlere ayrılan yukarıdan aşağıya yöntemleri tercih edilmektedir. Nanokristal teknolojisi ile ilaç endüstrisinde hâlihazırda tedavide onaylanmış olan ilaç moleküllerinin daha az yan etki, daha düşük dozlar ve daha hızlı etki başlangıcı sağlayarak yeni dozaj formlarının geliştirilmesi ve yeni ilaç moleküllerinin daha iyi bir biyoyararlanımla formüle edilebilmesi amaçlanmaktadır.

Anahtar Kelimeler: Nanokristal teknolojisi, Suda çözünür ilaçlar, Oral yol, Hazırlama yöntemleri

\section{ABSTRACT}

Nanocrystal technology enables the production of solid drug particles with a particle size below $1000 \mathrm{~nm}$ without the need for any carrier system. By reducing the size of the particles of drugs with low solubility in water, increasing the surface area and decreasing the thickness of the diffusion layer leads to an increase in $\mathrm{k}$ the solubility rate. Accordingly, the increasing concentration gradient in the absorption zone promotes permeation and absorption by passive diffusion between the intestinal lumen and blood. Therefore, it is very important to improve and / or increase their bioavailability by using the nanocrystal technology approach for drug molecules belonging to BCS Class II and IV. Top-down and bottomup methods are used to obtain nanometer-sized drug particles. In the pharmaceutical industry, top-down methods, which are subdivided into wet milling (BWM) and high pressure homogenization ( $\mathrm{HPH})$, are preferred in the ball mill because of its ease of application, repeatability and scalability. With nanocrystal technology, it is aimed to create new dosage forms by providing less side effects, lower doses and faster onset of action of drug molecules that are already approved in the pharmaceutical industry. It is also aimed that new drug molecules can be formulated with better bioavailability.

Keywords: Nanocrystal technology, Water-soluble drugs, Oral route, Methods of preparation

\section{GiRiş}

Kombinatoryal kimya ve ilaç molekülü tasarımında ortaya çıkan eğilimler, daha çok lipofilik, yüksek molekül ağırlığına sahip ve sudaki zayıf çözünürlüğü olan ilaç molekülü adaylarının gelişmesine yol açmıştır. Bu nedenle keşif veya geliştirme aşamasında olan ilaç adayları kümesinin formüle edilmeleri giderek zorlaş- maktadır. Geriye dönük ve ileriye dönük analizlerle pazardaki ilaçların \%40'nın, yeni geliştirilen ilaçların ise yaklaşık \%90'nın zayıf çözünür olduğu gösterilmiştir (1-3).

Biyofarmasötik sınıflandırma sistemi (BCS), biyofarmasötik açıdan formülasyon geliştirmede çok yararlı bir yaklaşımdır. BCS sınıf II ve IV ilaç moleküllerinin oral yol ile uygulanmaları sonra-

Sorumlu Yazar/Corresponding Author: Yıldız ÖZSOY E-mail: yozsoy@istanbul.edu.tr

Başvuru/Submitted: 09.10.2020 • Kabul/Accepted: 19.11.2020 • Online Yayın/Published Online: 20.10.2021 
Sı, yeterli oranda ve tekrarlanabilir biyoyararlanım elde etmek için iyi tasarlanmış formülasyonlar gereklidir. Genellikle BCS Sınıf II'ye ait bir ilaç molekülünün biyoyararlanımı çözünme ile sınırlıyken BCS Sınıf IV'e ait bir etken maddenin emilimi için hem çözünürlük hem de permeabilite hız sınırlayıcı basamaklardır (4, 5). Geliştirilebilirlik sınıflandırma sistemine (DCS) göre BCS Sınıf II'ye ait ilaç molekülleri Sınıf Ila ve Sınıf Ilb olarak alt sınıflara ayrılmıştır (Şekil 1). DCS, ilaç moleküllerinin in vivo davranışını ve hassasiyetlerini değerlendirmek, in vivo performansı için hangi faktörlerin daha önemli olduğunu belirlemek için daha uygun bir şekilde sınıflandırmayı sağlar (6).

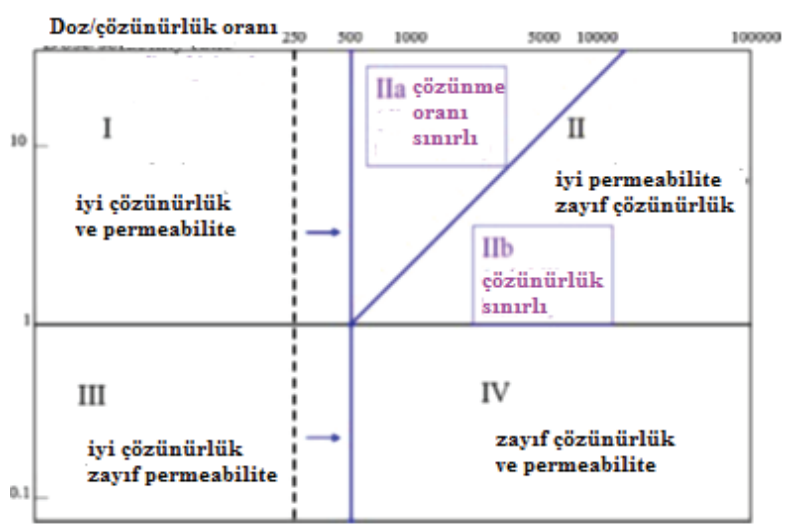

Şekil 1: GI kanalda gerçeği daha çok yansıtan sıvı miktarları ve düşük çözünürlükte permeabilitenin telafi edici doğası için BCS sisteminin modifiye edilerek DCS sistemi geliştirilmiştir (6)

DCS sistemi aşağıdaki kavramları birleştirmeyi amaçlamaktadır: $(6,7)$

- Emilimin derecesinin tahmini için in vivo çözünürlüğün birincil ölçüsü olarak yararlı olan açlık durumunda insan barsak çözünürlüğünün değerlendirilmesi

- Çözünürlük sınırlı emilebilir doz (SLAD) kavramı, sınıf II ilaçlar için emilim ve çözünürlüğün dengeleyici olduğu fikrine dayanmaktadır.

- Doz/çözünürlük oranından (çözünürlük hızı, kısıtlayıcı ilaçlar için) daha önemli olan hedef partikül büyüklüğü olarak ifade edilen çözünürlük hızı

DCS Sınıf Ila'da çözünme hızı kısıtlayıcı iken, DCS Sınıf Ilb için çözünürlük sınırlayıcıdır. Sınıf Ilb molekülleri dozaj şeklinde hâlihazırda çözünmüş bir şekilde formüle edilmedikçe tam olarak emilme eğilimi göstermezler. Kat dispersiyonlar ya da lipit bazlı sistemlerle formüle edilebilirler. Çözünme hızı, emilim bölgesinden geçiş süresi boyunca çözünemeyecek kadar yavaş olan sınıf Ila moleküller için standart bir formülasyondan ilaç salımını etkileyen partikül büyüklüğü, yüzey alanı ve ıslanabilirlik gibi faktörlerin kontrol edilmesi tamamen emilimin sağlanmasında kritik öneme sahip olacaktır $(6,7)$.

Klinikte, suda az çözünür ilaçların geleneksel yöntemlerle hazırlanan formülasyonları sıklıkla zayıf ve yüksek oranda değiş- ken biyoyararlanım göstermeleri nedeni ile sıkıntılıdırlar. Dozaj formları çoğu kez hastanın açlık- tokluk durumundan etkilenir, etki beklenenden daha geç başlamakta ve uygun olmayan dozlama ve zayıf performans göstermektedirler (8). Bahsedilen ilaçların biyoyararlanımlarını iyileştirmek için tuz oluşumu; yardımcı çözücü, siklodekstrinler gibi kompleksleştirici ajan kullanımı; mikronizasyon; katı dispersiyonlar; kat lipid nanopartiküller gibi pek çok yaklaşım geliştirilmiştir. Çok fazla miktarda yardımcı madde kullanımından dolayı bu stratejilerin bazıları başarıyla kullanılmaktadır ancak çoğu düşük miktarda ilaç yükleme kapasitesine sahiptir. Dolayısıyla, günlük olarak yüksek dozda kullanılması gereken ilaçlar için yüksek miktarda ilaç yükleme kapasitesine sahip formülasyonların geliştirilmesi giderek artan bir ihtiyaçtır. Diğer formülasyon stratejilerinin aksine, ilaç nanokristalleri ise neredeyse $\% 100$ etken madde ve sadece çok az miktarda stabilize edici madde içerdiklerinden bu gruptaki etken maddeler için yüksek yükleme kapasitesine sahiptirler (9).

1990'I ı yılların başında farmasötik alana sunulan nanokristal teknolojisi (10) ile partikül boyutu 1000 nm'den küçük kristal halde kat ilaç partikülleri elde edilir. Partiküllerin boyutunun küçültülmesi, yüzey alanını artırarak difüzyon tabakasının kalınlığını azaltarak suda çözünürlüğü zayıf olan ilaçların çözünme hızında artş̧a yol açar $(11,12)$. Bu nedenle BCS Sınıf II ve IV bileşikleri teorik olarak bazı istisnalar ile birlikte nano boyutlandırma için iyi adaylardır. Ayrıca küçük boyutları nedeniyle kendi mikronize ilaç partikülleri özelliklerinden belirgin bir şekilde farklı özelliklere sahiptirler (13).

Diğer nanopartiküler ilaç taşıyıcı sistemlere göre nispeten daha düşük maliyet, daha yüksek ilaç yükleme kapasitesine sahiptirler, bu nedenle formülasyonda kullanılan taşıyıcı sisteme bağlı yan etkileri hiç ya da daha çok az gösterirlerken, farmakokinetik değişkenlikleri en aza indirirler (14). Özellikle formülasyonun basitliği, yüksek ilaç yükleme yeteneği ve ölçek büyütme kolaylığı endüstri tarafindan kabul edilebilmesini sağlamıştır. Bazı ilaç moleküllerinin nanokristal teknolojisi ile geliştirilen farmasötik ürünleri 2000 yılından beri FDA tarafindan onaylanmıştır. Günümüzde farklı klinik fazlarda araştırmaları devam eden moleküllerde bulunmaktadır (15).

Nanokristaller temel olarak partikül büyüküğünü nano boyuta kadar indiren yukarıdan aşağıya (top-down) ve bir yardımcı çözücünün içinde antisolvent yardımı ile partiküllerin çöktürülmesine dayanan aşağıdan yukarıya (bottom-up) yöntemleri ile hazırlanırlar. Yukarıdan aşağıya yöntemler, uygulama kolaylığı ve ölçeklenebilirliği nedeniyle endüstride daha yaygın olarak kullanılmaktadır (16).

Nanokristaller sulu bir ortamda dispers edildiklerinde nanosüspansiyon olarak ifade edilmektedirler. Yüzey alanındaki dramatik artış Gibbs serbest enerjisini arttırdığından, termodinamik olarak kararlı olmayan bir sistemin oluşmasına yol açar, bu durumda moleküller enerjisini azaltmak için bir araya toplanma eğilimi gösterirler. Dolayısıyla sistemi kararlı hale getirmek için stabilizatörlere ihtiyaç duyulmaktadır. Nanosüspansiyonları stabilize etmek için sterik engelleme (entropik bariyer) ve elektrostatik stabilizasyon olmak üzere iki temel yaklaşım uy- 
gulanmaktadır. Polimerler ve iyonik olmayan yüzey etkin maddeler nanokristal yüzeyine adsorbe olarak sterik engellemede kullanılırken, yüklü moleküller elektrostatik itmeyi indükleyerek elektrostatik kararlılığı sağlamak için kullanılmaktadır $(11,17)$.

\section{Nanokristal Teknolojisinin Karakteristikleri}

\subsection{Yüksek Çözünme hızı}

Noyes-Whitney denklemi, partikül boyutunun küçültülmesi ile yüzey alanının artması ve difüzyon tabakası kalınlığının azalmasına bağlı olarak iyileştirilmiş bir çözünme hızının nasıl sağladığını tanımlamaktadır. Örnek olarak küresel partikülleri verecek olursak yüzey alanı hacme göre A / V = 3 / r'dir. Bu, partikül büyüklüğü $50 \mu$ m'den (yığın ilaç için partikül büyüklüğü) 500 nm'ye (ilaç nanokristalleri) düşürüldüğünde aşağıda formülü verilen Noyes-Whitney denklemine göre çözünme hızındaki artışın 100 kat olduğu anlamına gelmektedir $(18,19)$.

$$
\frac{d C}{d t}=\frac{D S}{V h}(C s-C)
$$

dC/dt: Çözünme hızı (zamanın bir fonksiyonu olarak konsantrasyon değişimi), D: Difüzyon katsayısı, S: Yüzey alanı, V: Çözünme hacmi, h: Difüzyon tabakası kalınlığı, Cs: Doygunluk konsantrasyonu ve $\mathrm{C}$ : t zamanındaki konsantrasyondur.

\subsection{Yüksek doygunluk çözünürlüğü}

Doygunluk çözünürlüğü; kristal yapısı (örgü enerjisi) ve partikül büyüklüğü gibi bileşiğin fizikokimyasal özelliklerine, çözünme ortamına ve sıcaklığa bağlı olarak bileşiğe özgü bir sabittir. 1000 nm'nin altında doygunluk çözünürlüğü artmaktadır. İlacın doymuş çözünürlüğü (Cs) ile partikül büyüklüğü ( $r$ ) arasındaki ilişki Ostwald-Freundlich denklemi ile doğrudan açıklanmaktadır (20).

$$
\frac{\log C s}{\log C \alpha}=\frac{2 \sigma V}{2.303 R T \rho r}
$$

Cs: Doygunluk çözünürlüğü, $C \alpha$ : Büyük partiküllerin çözünürlüğü,

$\sigma:$ Maddenin arayüzey gerilimi, $\mathrm{V}$ : Partiküllerin

molar hacmi,

R: Gaz sabiti, T: Mutlak sıcaklık, p: Katının yoğunluğudur ve r: Yarıçaptır

Böylece doygunluk çözünürlüğünde artş iki avantaj sunmaktadır;

-Noyes-Whitney denklemine göre artmış konsantrasyon gradientinden $((\mathrm{CS}-\mathrm{Ct}) / \mathrm{h})$ dolayı artmış çözünürlük hızı,

-Barsak lümeni ve kan arasındaki pasif difüzyon yoluyla permeasyon ve emilimi teşvik eden artmış konsantrasyon gradientidir.

\subsection{Aşırı doymuşluk durumu}

Amorf formülasyonlara benzer şekilde, ilaç nanokristallerinin termodinamik çözünürlüğe kıyasla daha yüksek görünür çözü- nürlüğü nedeniyle, ilaç nanokristalleri termodinamik olarak kararsız olan aşırı doymuş bir durum meydana getirmektedir (18).

\section{Nanokristallerin Hazırlanmasında Formülasyon Yaklaşımları} 2.1. Yukarıdan Aşağıya Yaklaşımı

Yaş öğütme işlemi; asılı ilaç partiküllerinin cam, zirkonyum oksit veya oldukça çapraz bağlı polistiren reçineleri gibi öğütme ortamları kullanılarak mekanik olarak aşınmasından yüksek basınçlı homojenizasyon yöntemi ise çok küçük bir boşluktan çok yüksek bir hızda bir süspansiyonu tekrar tekrar zorlayarak partikül boyutunun küçültülmesinden ibarettir. Tipik olarak bu üretim işlemleri sıvı içinde yürütülür. Dolayısıyla bir nanosüspansiyon oluşturur ve ayrıca başarılı bir nanosüspansiyonun üretimi için seçilen stabilizatör ve konsantrasyonu çok önemlidir $(21,22)$.

\subsubsection{Bilyeli Değirmende Yaş Öğütme}

Mikron büyüklüğündeki ilaç kristallerinin su bazlı stabilize edici bir çözeltide öğütüldüğü bir aşındırma işlemidir (NanoCrystal ${ }^{\circledR}$ Teknolojisi). Şekil 2'de gösterilen etken madde ile birlikte stabilizatör içeren dispersiyon ortamı (genellikle su) öğütme bölmesine yüklenir, ilaç konsantrasyonu genellikle $1-400 \mathrm{mg} / \mathrm{ml}$ arasındadır. Sterik veya iyonik bariyer oluşturarak etkili olan stabilize edici maddeler ilaç nanokristallerinin yüzeyini yeterince ıslatabilmeli, ilaç/stabilizatör madde oranı 20:1 ile 2:1 arasında fiziksel olarak stabil nanokristal dispersiyonlar elde edilebilmektedir. Öğütme hareketinin meydana getirdiği yüksek enerji ile oluşan kesme kuvvetleri ilaç kristallerini nanometre boyutuna indirmek için gerekli enerji girdisini sağlayarak partikül boyutunun küçülmesine yol açar. Ögütme süresi esas olarak ilacın sertliğine, viskozitesine, sıcaklığa, enerji girdisine, öğütme ortamının büyüklüğüne ve kullanılan sürfaktan konsantrasyonuna bağlıdır. İşlem bir parti halinde veya geri dönüşümlü olarak gerçekleşebilmektedir. NanoCrystal ${ }^{\circ}$ teknolojisi; oral, inhalasyon, intravenöz, subkutan, intramüsküler ve oküler uygulama için nanosüspansiyonların kullanımını sağlamıştır $(8,23)$.

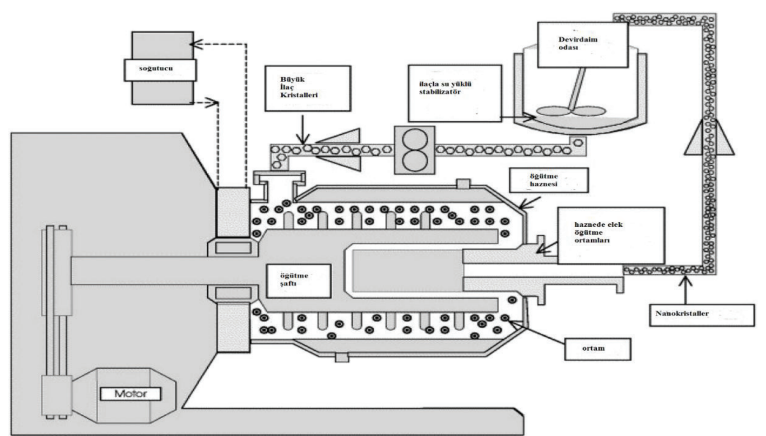

Şekil 2: Öğütme işleminin şematik gösterimi (8)

Liu ve ark. yaş öğütme yöntemi ile 4 farklı konsantrasyonda 4 tip stabilizatör ve yapısal olarak farklı, düşük çözünürlüklü bileşikler olan indometazin ve itrakonazol ile nanosüspansiyon hazırlamışlardır (24). Stabilize edici maddeler; F68, F127, Tween 80 ve PEG 6000 ağırıkça sırasıyla \%10, \%25 \%60 ve \%80 konsantrasyonlarda kullanılmıştır. Foton korelasyon spektroskopisi (PCS) sonuçlarına göre en iyi nanosüspansiyonlar \%80 Pluronic F68 ve \%60 Pluronic F27 konsantrasyonlarında elde edilmiştir. Amfifilik blok kopolimerleri (F127 ve F68), düşük moleküler 
ağırlıklı yüzey aktif maddeden (Tween80) daha etkili göründüğünü bildirmişlerdir.

\subsubsection{Yüksek Basınçlı Homojenizasyon}

Yüksek başınçlı homojenizasyon yaklaşımı, iki temel homojenizasyon prensibi ile çalışan mikro-akışkanlaştırma (micro-fluidization) ve piston-açıklıklı homojenizatörler ile yürütülmektedir (25).

\subsubsection{Mikroakışkanlaştırıcı Teknoloji}

Çözünmeyen İlaç Taşıyıcı Partikülleri (IDD-P'M) teknolojisi olarak da adlandırılan Mikroakışkan teknolojisi, jet akış homojenizatörleri kullanmaktadır. Etken madde genellikle su olan dispersiyon ortamında süspande edilir ve 1700 bara kadar basınç uygulanan bir bölmede iki yüksek enerjili sıvı akışının önden çarpışmasıyla küçük partiküller üretilir, bu durumda partikül çarpışmasına, kesme kuvvetlerine ve kavitasyon kuvvetlerine yol açmaktadır (Şekil 3A). İstenilen boyuta ulaşmak için 50-100 kere yapılan tekrarlama işlemi, öğütme yöntemine kıyasla zaman alıcı hale getirmektedir. Bu teknikte kat dispersiyonlar için kullanılan Z tipi ve emülsiyon, lipozom gibi sıVı-sıvı dispersiyonlar için Y tipi olmak üzere iki farklı tipte etkileşim odası kullanabilir (Şekil 3B) $(13,25)$.

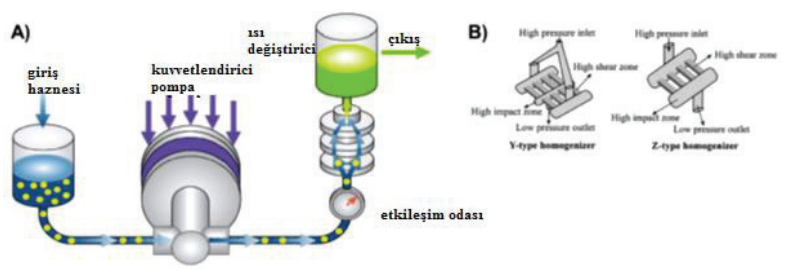

Şekil 3: Mikroakışkanlaştırıcı Teknolojinin şematik gösterimi

(A) Nanokristal üretimi için kullanılan kurulum ve (B)

Homojenleştirme odası tipleri (25)

\subsubsection{Piston Açıklıklı Homojenizatörler}

Homojenizasyon, saf suda (Disso-Cubes ${ }^{\circledR}$ teknolojisi) veya susuz/suyu azaltılmış ortamda (Nanopure ${ }^{\circledR}$ teknolojisi) yapılabilir. Müller ve ark. tarafindan 1990 'ların ortalarında Disso-Cubes ${ }^{\circledR}$ teknolojisi geliştirilirken milenyumun başında ilaç partiküllerinin sulu olmayan ortamlarda veya azaltılmış su içeriğine sahip dispersiyon ortamlarında (su-PEG veya su-gliserol gibi suyla karışabilen sıvılarla) homojenleştirilmesine dayanan ikinci nesil Nanopure ${ }^{\circledR}$ teknoljisi geliştirilmiştir (Şekil 4'te her iki teknolojisinin mekanizmaları gösterilmiştir.) (7).

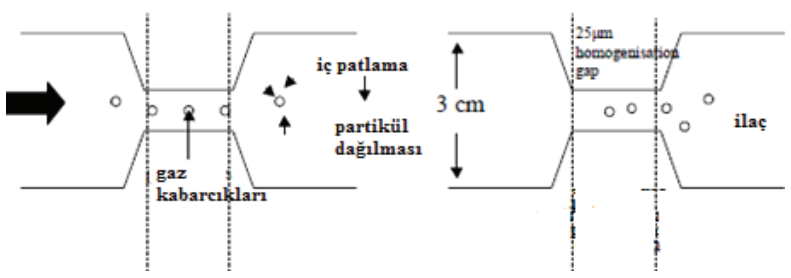

Şekil 4: Bir piston açıklı homojenizatörde akış dispersiyonunun çapının, kaba süspansiyonu içeren silindirden dar homojenizasyon boşluğuna değiştirilmesi şematize edilmiştir (sol taraf: suda homojenizasyon, sağ taraf: su karışımlarında veya susuz ortamda homojenizasyonu göstermektedir) (37).

\subsection{Sulu Ortamda Yüksek Basınçlı Homojenizasyon (Dis- so-Cubes ${ }^{\circledR}$ Teknolojisi)}

Mikronize boyutta süspansiyonlar, son derece yüksek bir hızda çok ince bir boşluktan (genellikle $25 \mu \mathrm{m}$ ) geçer. Boşluğa girmeden önce, süspansiyon boşluğun genişliğine kıyasla nispeten daha büyük bir çapa (genellikle $3 \mathrm{~cm}$ ) sahip bir silindir içinde bulunur. Bernoulli'nin yasalarına göre (26) , kesit başına kapalı bir sistemdeki sıvının akış hacmi sabittir. Bu, çaptaki azalmanın dinamik basınçta çok büyük bir artş̧a ve aynı zamanda sıvı ince boşluktan geçerken statik basıncın azalmasına yol açtı̆ı anlamına gelmektedir. Statik basınç, suyun buhar basıncının altına düşer ve sıvının kaynamasına neden olur. Süspansiyon boşluktan ayrılırken, basınç aniden normal basınca yükselir ve buhar kabarcıkları uzaklaştırılır (26).

İlaç nanokristallerinin büyüklüğü esas olarak homojenizatörün güç yoğunluğu, homojenizasyon döngü sayısı ve sıcaklığa bağlıdır. Homojenizasyon basıncı ne kadar yüksek olursa, boşluktaki sıvının hızı o kadar yüksek olur ve statik basınç daha büyük bir oranda düşmektedir. Daha fazla kabarcık oluşarak partikülleri küçültmek için daha yüksek enerjiye yol açar ve ilaç nanokristallerinin üretimi için maksimum basınca (genellikle laboratuar basıncı için 1500 bar) ihtiyaç vardır. Artan döngü sayısı, kristalin parçalanması için daha fazla enerji sağlamaktadır $(27,28)$.

\subsection{Organik Çözücüde Yüksek Basınçlı Homojenizasyon (Nanopure ${ }^{\circledR}$ Teknolojisi)}

Homojenizasyonu düşük buhar basıncı ve düşük sıcaklıkla yürüten Nanopure teknolojisinde yağ, PEG gibi su içermeyen veya glisreol/su gibi suyla karışabilen ortamlar kullanılmaktadır. Sıvı nanosüspansiyonların kuru ürünlere dönüştürülmesi için, azaltılmış su içeriğine ve daha uçucu bir dispersiyon ortamına sahip süspansiyonlara sahip olmak avantaj sağlayabilmektedir (29).

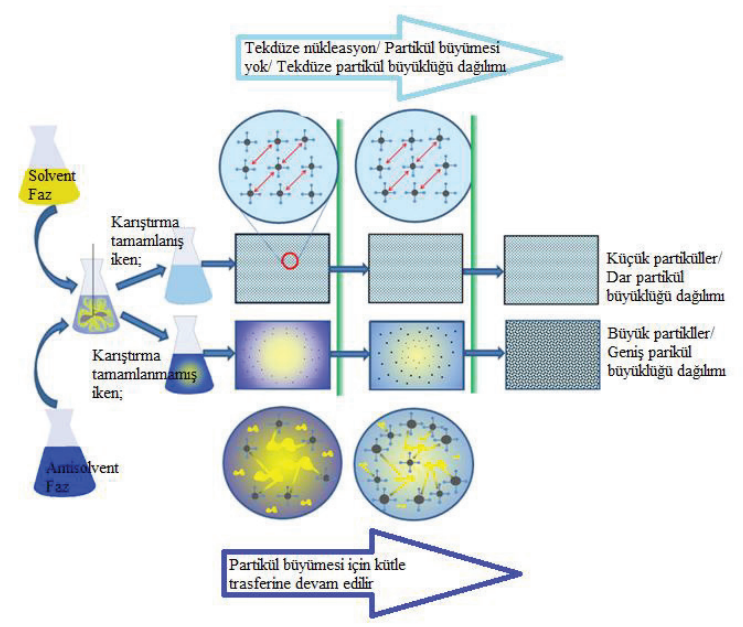

Şekil 5: Karışımın nihai parçacık büyüklüğü üzerindeki etkisinin şematik gösterimi. Tam karıştırma, tekdüze ve tam çekirdeklenme oluşturmaya yardımcı olurken, eksik karıştırma, eksik çekirdeklenmeye neden olur ve büyümeye devam etmektedir (39)

Gora ve ark., 3 faktörlü ve 3 seviyeli Box-Behnken tasarımını kullanarak suda çözünürlüğü az olan ve düşük biyoyararlanım 
gösteren valsartanın, yüksek basınçlı homojenizasyon yöntemi ile nanosüspansiyonunu hazırlamışlardır (30). 500 barla başlayan homojenizasyon basıncı 1000 barla devam etmiş ve 1500 bar basınç 5 döngü ile optimize edilmiş ve en düşük partikül boyutunu vermiştir.

Li ve ark. etken maddenin fizikokimyasal özelliklerinin suda az çözünür etken maddelerle hazırlanan nanosüspansiyonların biyoyararlanımına etkisini araştırmak için yüksek basınçlı homojenizasyon yöntemini kullanmışlardır (31). BCS Sınıf II bileşiklerinden model ilaç olarak seçilen albendazol, fenofibrat, itrakonazol, probukol ve revaprazan hidroklorür; farklı moleküler ağılık, log P değerleri, erime noktaları ve polar yüzey alanları nedeniyle model ilaç olarak seçilmişlerdir. Etken maddelere 850 - 1200 bar arasında değişik değerlerde basınç uygulayarak 428.2 - 463.2 arasında partikül büyüklüğü elde edilmiştir. Sonuçlar erime noktası daha küçük, log P değeri 5 civarında ve polar yüzey alanı değeri 50-60 aralığında olan etken maddelerin eğri altında kalan alanın $\left(\mathrm{AUC}_{\text {0àt }}\right.$ ) daha yüksek olduğunu göstermiştir.

\subsection{Aşağıdan Yukarıya Yaklaşımı}

2.2.1. Çözücü ve organik çözücü eklenmesiyle çöktürme yöntemi

Çözücü/anti-çözücü yöntemi, suda az çözünür etkin maddenin organik çözücü (suyla karışabilir) içindeki çözeltisinin bir anorganik (anti-çözücü) ortamla (genellik su veya sulu ortam) yoğun bir şekilde karıştırılmasına dayanır. Organik çözücünün anorganik ortama hızlı difüzyonu aşırı doygunluk durumunu meydana getirir, böylece mikron alt partiküllerin üretimine yol açan çekirdeklenme oranı artar ve partikül büyümesi gerçekleşir (32).

Çöktürme yöntemi; ölçek büyütme potansiyeli, basit ve uygun maliyetli yaklaşımlarıyla ilaç endüstrisinde kesintili işlemden sürekli bir imalat sürecinin gereklerini karşılamaktadır. Dondurarak kurutma ve püskürtmeyle kurutma, nanosüspansiyonları yeniden dağılabilir kuru tozlara dönüştürmek için yaygın olarak kullanılan iki yöntemdir (33).

Xia ve ark., nitrendipinin çözünme hızını ve oral biyorarlanımını arttırmak için çöktürme-ultrasonikasyon yöntemi ile nanosüspansiyonunu hazırlamışlardır (34). Çöktürme yönteminde çökmeden sonra genellikle hızlı bir büyüme hızına sahip oldukları için oluşan partiküllerin büyüklüğünü kontrol etmek zordur, bu açıdan son 10 yılda çekirdeklenme ve kristalleşme sürecini kontrol etmek için etkili bir yöntem olarak dikkat çekmektedir. Sıçanlarda yapılan in vivo çalışma ile, nanosüspansiyonun uygulanması ile elde edilen Cmaks ve AUCO $\rightarrow 12$ değerlerinin, ticari tabletlerden sırasıyla yaklaşık 6.1 kat ve 5.0 kat daha yüksek olduğunu göstermiştir.

\subsubsection{Süperkritik Akışkan Teknolojisi}

Süperkritik duruma dönüşmeyi kolaylaştıran ortam sıcaklığına yakın kritik sıcaklığı (yaklaşık $31^{\circ} \mathrm{C}$ ) ve nispeten düşük kritik basıncı (73,8 bar) nedeniyle çoğunlukla karbonsioksit kullanılmaktadır. Süperkritik karbondioksit (SCO2) çözeltisinin düşük polaritesi nedeniyle, hidrofobik ilaçlar kolayca karışır ve bir çözelti oluşturur, daha sonra bu çözeltinin bir kılcal tüp yoluyla genleşmesi ve ince ilaç partiküllerinin formüle edilmesi sağlanmaktadır $(35,36)$.

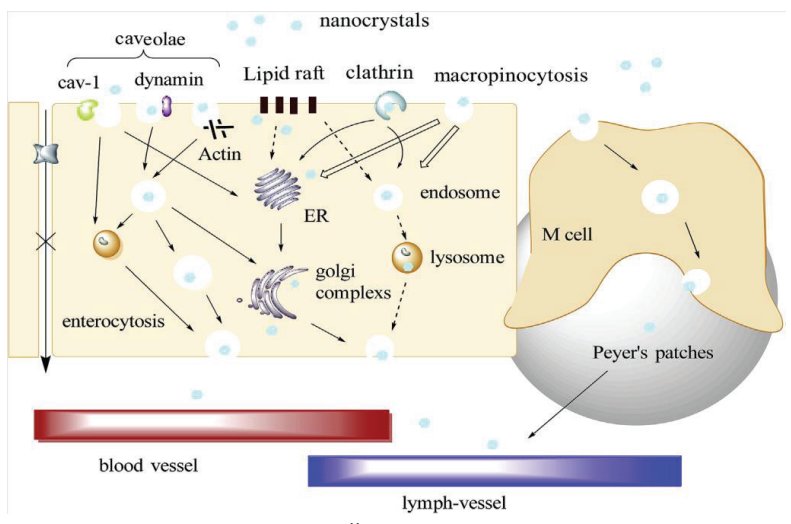

Şekil 6: Nanokristallerin bağırsak membranı boyunca hücresel transport mekanizmaları (37)

\subsection{3 Çözücü Buharlaşması Yöntemi}

Dondurarak kurutma ve püskürterek kurutma, çözücü uzaklaştırma işlemlerine giren iki yöntemdir. Ancak her iki yöntemde de tek başına nanometre boyutunda ürün elde edebilmek için geliştirilmiş sıvı atomizasyon tekniği gereklidir. Püskürterek kurutma tekniğinde partikül boyutunu etkileyen ana faktörlerin prekürsör (damlacık formuna dönüşmek için atomizasyon ekipmanını besleyen ilk sıvı/bulamaç) konsantrasyonundaki bir azalma ve seçilen atomizer tipi olduğu düşünülmektedir (37).

\section{Nanokristal Teknolojisiyle Hazırlanan İlaçların Oral Yoldan Ab- sorpsiyon Mekanizmaları}

Oral yoldan uygulanan nanokristal ilaçların gastrointestinal kanaldan kan veya lenfatik sisteme geçişi; iyileştirilmiş doygunluk çözünürlüğü ve çözünme hızı, mukus tabaka ile artmış etkileşim, barsak membranı boyunca artmış transport ve genellikle stabilize edici maddelerle desteklenmiş diğer yöntemler olmak üzere kompleks mekanizmalarla sağlanmaktadır (35).

- İyileştirilmiş doygunluk çözünürlüğü ve çözünme hızı: Yukarıdaki mekanizmalarla açıklandığı gibi nano boyutta partikül büyüklüğü nedeniyle artmış çözünürlük hızı ve doygunluk çözünürlüğü ile mukozada daha yüksek bir ilaç konsantrasyonu oluşturulur, böylece gastrointestinal membran ve kan damarları arasında ilacın daha yüksek ilaç konsantrasyon gradyanı elde edilebilir ve ilaçların biyoyararlanımı artabilmektedir $(35,38)$.

- Mukus tabaka ile artmış etkileşim: Küçük partikül büyüklüğü ve nanokristaller ile mukoza arasındaki elektrostatik etkileşimleri artırabilecek pozitif yüklü fonksiyonel stabilizatör maddelerin potansiyel kullanımı sayesinde nanokristaller daha yüksek elektrostatik çekim kuvvetleri, van der Waals kuvvetleri, penetrasyon ve etkileşim gösterebilmektedir. Mukoadezyonun iyileştirilmesi ile ilaçların kalış süresi uzatılır, bu sayede absoprsiyon bölgesinde etken maddenin salımı için rezervuar oluşarak ağ benzeri bir yapıya sahip müsin molekülleri ile ilacın alttaki epitele difüzyonu düzenlenebilmektedir $(20,39)$.

- Barsak membranı boyunca artmış transport: Nanokristaller, epitelyal hücreler tarafindan caveolin, caveola, ve makrofaj aracılı endositoz yoluyla alınabilmektedir ve giriş yapan nanokristaller epitelyal hücre boyunca Golgi kompleksleri, lizozomlar 
ve endozomlar yardımıyla ve Peyer yamaları içindeki M hücreleri tarafindan alınabilir ve lenf damarına taşınabilmektedir (40-42).

\section{Nanokristallerin Oral Yoldan Uygulanması}

Genellikle oral yolla ilaç alımında çözünürlük hız sınırlayıcı basamaktır. BCS Sınıf II ve IV'e ait ilaçlar genellikle tam çözünmeden önce gastrointestinal kanaldan elimine edilme eğiliminde olup yavaş ve düzensiz çözünürlükleri hızlı ve tam olarak absorbe edilmelerini önlemektedir. İlaç nanokristalleri şeklinde formüle edilmeleri çözünürlük hızı ve doygunluk çözünürlüğü ile barsak duvarına biyoadezyonu iyileştirerek (Şekil 7A) maksimum plazma konsantrasyonu $\left(C_{\text {maks }}\right)$, kan konsantrasyonu-zaman eğrisi (AUC) altında kalan alanı arttrırken doruk plazma konsantrasyonuna varış süresi ( $\left.T_{\text {maks }}\right)$ ve açlık/tokluk durumu değişkenlikleri azalmaktadır (Şekil 7B ve 7C).

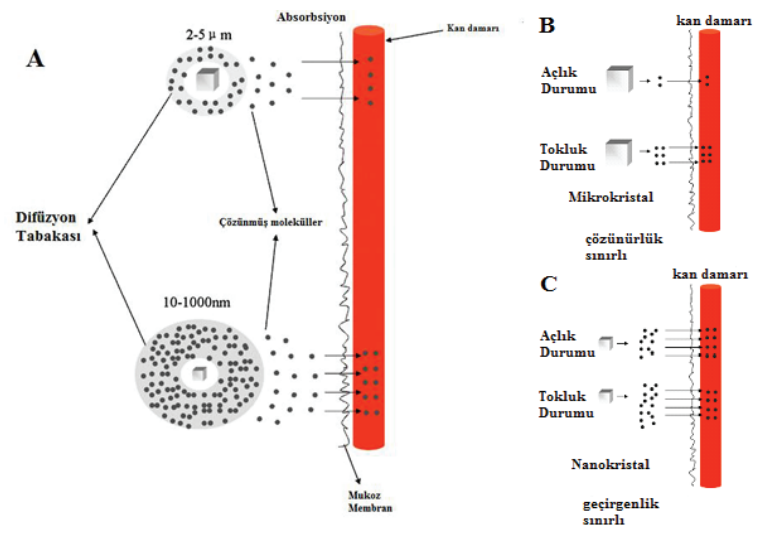

Şekil 7: Gastrointestinal kanal ve kan damarı arasında yüksek bir ilaç konsantrasyon gradienti oluşturur ve emilimde önemli bir iyileşmeye yol açar (57)

Fu ve ark.'nın mikroçöktürme-yüksek basınçlı homojenizasyon yöntemiyle hazırladıkları, ortalama partikül çapı yaklaşık $833.3 \mathrm{~nm}$ olan Nimodipin nanokristallerinin ticari preperat olan
Nimotop”a göre farklı ortamlarda düşük çözünürlük profili göstermesine karşın biyoyararlanımının yaklaşık 2.6 kat daha fazla olduğunu tespit etmişlerdir ve bu olumsuz in vitro /in vivo korelasyonunun mekanizmasını araştırmışlardır (43). Araştırma sonucunda nanokristallerin bazı kısımlarının enterositler tarafindan makropinositoz/caveolin aracılı endositoz ve $\mathrm{M}$ hücreleri tarafindan alınıp mezentrik lenf kanalına boşaltıldığı, böylece karaciğerden ilk geçiş metabolizmasını atladığı ve biyoyararlanımının artmasına neden olduğu bulunmuştur.

Müller ve ark. protozoa paraziti Cryptosporidium parvum enfeksiyonlarında kullanılan Buparvakuon'un oral uygulanması için nanosüspansiyonunu hazırlamışlar ve formülasyonun mukoadezif özelliklerini arttırmak için mukoadezif hidrojelleri de formülasyona dahil etmişlerdir (44). İyonik olmayan yüzey etkin madde olan Poloksamer ve Polivinil alkol sterik, amfifilik olan lesitin elektrostatik stabilizasyon sağlamak için kullanılmıştır. Ağırlıkça \%0.5 lesitin, \%1 poloksamer, \%1 buparvakuon içeren ve $\% 2.5$ buparvakuon ve $\% 0.5$ poloksamer 188 içeren formülasyonlar teorik olarak minimum elektrostatik stabilizasyon için $-30 \mathrm{mV}$ ve sterik stabilizasyon için $-20 \mathrm{mV}$ zeta potansiyeli 6 ay boyunca sağlamışlardır.

Fu ve ark. öğütme yöntemiyle değişik stabilize edici maddeler ve öğütme süresinin ayarlanmasıyla 1227.7, 472.7 ve 240.3 nm boyutlarında nisoldipinin nanokristallerini elde etmişlerdir (45). in vitro çözünme çalışmaları, nanokristallerin çözünme oranlarının mikrokristallerinkinden çok daha hızlı olduğunu ve sıçanlarda yapılan farmakokinetik çalışmalar, oral absorpsiyonun boyuta bağlı olduğunu ve $240.3 \mathrm{~nm}$ büyüklüğündeki nisoldipin nanokristalleri üstün bir oral absorpsiyon göstermiştir.

Lai ve ark. lipofilik, suda az çözünür olan Piroksikam'ın çözünürlük özelliklerini optimize etmek için yüksek basınçlı homojenizasyon tekniği ve stabilize edici madde olarak Poloksamer 188 ile nanokristal yaklaşımını kullanılarak ağızda dağılan tablet (ODT) hazırlamışlardır (46). Piroksikamın nanosüspansiyonları

Tablo 1: FDA tarafından onaylanan nanokristal oral ilaç ürünleri $(35,47,48)$

\begin{tabular}{|c|c|c|c|c|}
\hline Ürün & Etken madde & Dozaj Şekli & Üretim Yaklaşımı & Onay Tarihi \\
\hline Gris-PEG ${ }^{\circledR}$ & Griseofulvin & Tablet & Çöktürme Yötemi & 1975 \\
\hline Celebrex $^{\circledR}$ & Selekoksib & Kapsül & & 1998 \\
\hline Rapamune $^{\circledR}$ & Sirolimus & Tablet & Yaş Öğütme & 2000 \\
\hline Focalin XR ${ }^{\circledR}$ & Deksmetilfenidat $\mathrm{HCl}$ & Uzatılmış salımlı kapsül & Yaş Öğütme & 2001 \\
\hline Ritalin LA ${ }^{\circledR}$ & Metilfenidat $\mathrm{HCl}$ & Kapsül & Yaş Öğütme & 2002 \\
\hline Zanaflex Capsules $^{\mathrm{TM}}$ & Tizanidin $\mathrm{HCl}$ & Kapsül & Yaş Öğütme & 2002 \\
\hline Emend $^{\circledR}$ & Aprepitant & Kapsül & Yaş Öğütme & 2003 \\
\hline Tricor $^{\circledR}$ & Fenofibrat & Tablet & Yaş Öğütme & 2004 \\
\hline Megace ${ }^{\circledR}$ ES & Megastrol asetat & Süspansiyon & Yaş Öğütme & 2005 \\
\hline Triglide $^{\mathrm{TM}}$ & Fenofibrat & Tablet & $\begin{array}{l}\text { Yüksek basınçlı } \\
\text { homojenizasyon }\end{array}$ & 2005 \\
\hline Cesamet $^{\circledR}$ & Nabilon & Kapsül & Çöktürme Yöntemi & 2005 \\
\hline
\end{tabular}


kullanılarak hazırlanan tüm ODT formülasyonları, kaba partikül boyutunda olan piroksikam ile hazırlanan ODT'ye kıyasla daha yüksek bir çözünme hızı göstermiştir. Çözünme hızındaki iyileşmenin esas olarak ilaç partiküllerinin mikron alt boyutundan dolayı artan yüzey / hacim oranından kaynaklandığı sonucuna varmışlardır.

Yukarıdaki çalışmalarla örneklendiği gibi nanokristal teknolojisi sürekli geliştirilmektedir. Günümüzde Amerikan Gıda ve İlaç Dairesi (FDA) tarafindan onaylanmış tablet, kapsül ve süspansiyon şeklinde oral yoldan uygulanan birçok preparat ilaç endüstrisinde yerini almıştrr, ayrıca ilaç endüstrisinde mevcut olan ve FDA'ya yapılan başvurularda en çok oral yoldan uygulanan preparatlar bulunmaktadır (47), Tablo 1'de gösterilmiştir.

Nanokristal teknoljisi ile hazırlanan preparatlar FDA'daki İlaç Değerlendirme ve Araşttrma Merkezi (CDER) tarafindan yeni araştirma ürünü ilaç başvurusu (INDs), yeni ilaç başvurusu (NDA), hızlandırılmış yeni ilaç başvurusu (ANDA) şeklinde alınmaktadır. Dolayısıyla yapılan bu başvurular nano boyuttaki ilacın aynı dozda uygulanan mikrokristal veya çözünmüş bir formuna biyoeşdeğer olmadığı için jenerik olarak kabul edilmez, yeni ilaç başvurusu olarak kabul edilir ve patentlenebilmektedir. Böylece yeni ilaç dozaj formları, ilaç endüstrisine ürün portföylerini geliştirmeleri için avantaj sağlarken daha az yan etki, daha düşük dozlar ve daha hızlı etki başlangıcı ile tedavide hastalara da yarar sağlanabilmektedir. Örneğin Rapamune (sirolimus) bir oral çözeltiden biyoyararlanımı \%21 daha yüksek olan nanokristal teknolojisi kullanılarak hazırlanan tablet dozaj formuna, Tricor ${ }^{\circ}$ (fenofibrat) mikronize halden nano ölçekli bir preparata, mikronize bir süspansiyon olarak geliştirilen Megace 'den nanokristal koloidal dispersiyondaki Megace ${ }^{\circ}$ ES (megestrol asetat) yeniden formüle edilmiştir (48-50).

\section{SONUÇ}

Nanokristal teknolojisi lipofilik, yüksek molekül ağırlıklı ve sudaki çözünürlüğü düşük olan özellikle BCS Sınıf II ve IV'e ait ilaç moleküllerinin çözünürlük hızı ve doygunluk çözünürlüğünü arttırarak biyoyararlanımını iyileştirilebilmekte ve/veya arttırılabilmektedir. Bu sınıflarda yer alan etken maddelerin oral yoldan verilmesiyle açlık/tokluk durumu değişkenlikleri ve doruk plazma konsantrasyonuna varış süresi ( $\left.T_{\text {maks }}\right)$ azalırken maksimum plazma konsantrasyonu ( $\left.C_{\text {maks }}\right)$, kan konsantrasyonu-zaman eğrisi (AUC) altında kalan alanı artmaktadır. İlaç endüstrisinde oral yoldan verilen ilaçlar en büyük kısmı oluşturmaktadır ve üretimleri diğer veriliş yollarına nazaran daha kolaydır. Sonuç olarak nanokristal teknolojisi, oral yoldan verilmesi istenen ilaç moleküllerinin nihai dozaj şekillerine getirilerek hasta kullanımına sunulması ile mevcut dozaj formlarına göre daha az yan etki, daha düşük doz ve daha hızlı etki başlangıcı ile hastaya uyuncunu arttırmakta ve aynı zamanda yeni ilaç moleküllerinin daha iyi bir biyoyararlanım gösterecek şekilde formüle edilmesini sağlamaktadır.
Yazar Katkıları: Çalışma Konsepti/Tasarım- Y.P.T., S.G., Y.Ö.; Veri Toplama- S.P.T.; Veri Analizi/Yorumlama- Y.P.T., S.G., Y.Ö.; Yazı TaslağıY.P.T.; İ̧eriğin Eleştirel İncelemesi- S.G., Y.Ö.; Son Onay ve SorumlulukY.P.T., S.G., Y.Ö.

Çıkar Çatışması: Yazarlar çıkar çatışması beyan etmemişlerdir

Finansal Destek: Yazarlar finansal destek beyan etmemişlerdir.

Peer Review: Externally peer-reviewed.

Author Contributions: Conception/Design of Study- Y.P.T., S.G., Y.Ö.; Data Acquisition-S.P.T.; Data Analysis/Interpretation- Y.P.T., S.G., Y.Ö.; Drafting Manuscript- Y.P.T.; Critical Revision of Manuscript- S.G., Y.Ö.; Final Approval and Accountability- Y.P.T., S.G., Y.Ö.

Conflict of Interest: Authors declared no conflict of interest.

Financial Disclosure: Authors declared no financial support.

\section{KAYNAKLAR}

1. Kalepu S, Nekkanti V. Insoluble drug delivery strategies : review of recent advances and business prospects. Acta Pharm Sin B 2015;5(5): 442-53.

2. Augustijns $P$, Wuyts $B$, Hens B, Annaert P, Butler J, Brouwers J. A review of drug solubility in human intestinal fluids : Implications for the prediction of oral absorption. Eur J Pharm Sci 2014;57:322-32.

3. Loftsson T, Brewster ME. Pharmaceutical applications of cyclodextrins : basic science and product development. J Pharm Pharmacol 2010;62: 1607-21.

4. Kawabata Y, Wada K, Nakatani M, Yamada S, Onoue S. Formulation design for poorly water-soluble drugs based on biopharmaceutics classification system : Basic approaches and practical applications. Int J Pharm 2011;420: 1-10.

5. Wu C, Benet LZ. Predicting Drug Disposition via Application of BCS : Transport / Absorption / Elimination Interplay and Development of a Biopharmaceutics Drug Disposition Classification System Pharm Res 2005;22(1): 11-23.

6. Butler JM, Dressman JB. The Developability Classification System : Application of Biopharmaceutics Concepts to Formulation Development. J Pharm Sci 2010;99(12): 4940-54.

7. Möschwitzer JP. Drug nanocrystals in the commercial pharmaceutical development process. Int J Pharm 2012;453: 14256.

8. Merisko-liversidge E, Liversidge GG, Cooper ER. Nanosizing : a formulation approach for poorly-water-soluble compounds. Eur J Pharm Sci 2003;18: 113-20.

9. Hou Y, Shao J, Fu Q, Li J, Sun J, He Z. Spray-dried nanocrystals for a highly hydrophobic drug : Increased drug loading, enhanced redispersity, and improved oral bioavailability. Int J Pharm 2017;516(1-2): 372-9.

10. Cheng M, Yuan F, Liu J, Liu W, Feng J, Jin Y, Tu L. Fabrication of Fine Puerarin Nanocrystals by Box - Behnken Design to Enhance Intestinal Absorption. AAPS PharmSciTech 2020: 1-12.

11. Soisuwan S, Teeranachaideekul V, Wongrakpanich A. Impact of uncharged and charged stabilizers on in vitro drug performances of clarithromycin nanocrystals. Eur J Pharm Biopharm 2019;137: 68-76. 
12. Seto $Y$, Ueno K, Suzuki H, Sato H, Onoue S. Development of novel lutein nanocrystal formulation with improved oral bioavailability and ocular distribution. J Funct Foods 2019;61: 103499.

13. Shah DA, Murdande SB, Dave RH. A Review : Pharmaceutical and Pharmacokinetic Aspect of Nanocrystalline Suspensions. J Pharm Sci 2016;105: 10-24.

14. Ren X, Qi J, Wu W, Yin Z, Li T, Lu Y. Development of carrier-free nanocrystals of poorly water-soluble drugs by exploring metastable zone. Acta Pharmacol Sinic 2019;9(1): 118-27.

15. Chen L, Wang Y, Zhang J, Hao L, Guo H, Lou H, Zhang D. Bexarotene nanocrystal - Oral and parenteral formulation development, characterization and pharmacokinetic evaluation. Eur J Pharm Biopharm 2014;87(1): 160-9.

16. Ferrar JA, Sellers BD, Chan C, Leung DH. Towards an improved understanding of drug excipient interactions to enable rapid optimization of nanosuspension formulations. Int J Pharm 2020;578: 119094.

17. Bitterlich A, Laabs C, Krautstrunk I, Dengler M, Juhnke $M$, Grandeury A, Bunyes H, Kwade A. Process parameter dependent growth phenomena of naproxen nanosuspension manufactured by wet media milling. Eur J Pharm Biopharm 2015;92: 171-9.

18. Peltonen L, Hirvonen J. Drug nanocrystals - Versatile option for formulation of poorly soluble materials. Int J Pharm 2018;537(1-2): 73-83.

19. Sarnes A, Kovalainen M, Häkkinen MR, Laaksonen T, Laru J, Kiessevara J, Ilkka J, Oksala O et al. Nanocrystal-based per-oral itraconazole delivery : Superior in vitro dissolution enhancement versus Sporanox ${ }^{\circledR}$ is not realized in in vivo drug absorption. J Control Release 2014;180: 109-16.

20. Buraphacheep V, Morakul B. Nanocrystals for enhancement of oral bioavailability of poorly water-soluble drugs. Asian J Pharm Sci 2015;10(1): 13-23.

21. He Y, Ye Z. Can machine learning predict drug nanocrystals? J Control Release 2020;322: 274-85.

22. Eerdenbrugh B Van, Mooter G Van Den, Augustijns P. Top-down production of drug nanocrystals: Nanosuspension stabilization, miniaturization and transformation into solid products. Int J Pharm 2008;364: 64-75.

23. Shegokar R, Müller RH. Nanocrystals : Industrially feasible multifunctional formulation technology for poorly soluble actives. Int J Pharm 2010;399(1-2): 129-39.

24. Liu P, Rong X, Laru J, et al. Nanosuspensions of poorly soluble drugs : Preparation and development by wet milling. Int J Pharm 2011;411(1-2): 215-22.

25. Fontana F, Figueiredo P, Zhang P, Hirvonen JT, Liu D, Santos HA. Production of pure drug nanocrystals and nano co-crystals by con fi nement methods. Adv Drug Deliv Rev 2018;131: 3-21.

26. Gao L, Zhang D, Chen M. Drug nanocrystals for the formulation of poorly soluble drugs and its application as a potential drug delivery system. J Nanopart Res 2008;10: 845-62.

27. Keck $\mathrm{CM}, \mathrm{Mu} \mathrm{RH}$. Drug nanocrystals of poorly soluble drugs produced by high pressure homogenisation. Eur J Pharm Biopharm 2006;62: 3-16.

28. Krause KP, Kayser O, Ma K, Gust R, Mu RH. Heavy metal contamination of nanosuspensions produced by high-pressure homogenisation. Int J Pharm 2000;196: 169-72.
29. Hui Z, Kumar A, Wan P, Heng S. ScienceDirect Overview of milling techniques for improving the solubility of poorly water-soluble drugs. Asian J Pharm Sci 2015;10(4): 255-74.

30. Gora S, Mustafa G, Sahni JK, Ali J, Baboota S. Nanosizing of valsartan by high pressure homogenization to produce dissolution enhanced nanosuspension : pharmacokinetics and pharma- codyanamic study. Drug Deliv 2016;23(3): 940-50.

31. Li W, Quan P, Zhang Y, Cheng J, Liu J, Cun D. Influence of drug physicochemical properties on absorption of water insoluble drug nanosuspensions. Int J Pharm 2014;460: 13-23.

32. Dong $\mathrm{Y}$, Kiong $\mathrm{W}, \mathrm{Hu}$ J, Shen $\mathrm{S}$, Tan RBH. A continuous and highly effective static mixing process for antisolvent precipitation of nanoparticles of poorly water-soluble drugs. Int J Pharm 2010;386: 256-61.

33. Hu J, Kiong W, Dong Y, Shen S, Tan RBH. Continuous and scalable process for water-redispersible nanoformulation of poorly aqueous soluble APIs by antisolvent precipitation and spray-drying. Int J Pharm 2011;404: 198-204.

34. Xia D, Quan P, Piao H, Sun S, Yin Y, Cui F. Preparation of stable nitrendipine nanosuspensions using the precipitation ultrasonication method for enhancement of dissolution and oral bioavailability. Eur J Pharm Sci 2010;40: 325-34.

35. Liu J, Tu L. Mechanisms for oral absorption enhancement of drugs by nanocrystals. J Drug Deliv Sci Technol 2020;56: 101607.

36. Shair I, Hu H, Yin L, He W. Drug nanocrystals : Fabrication methods and promising therapeutic applications. Int J Pharm 2019;562: 187-202.

37. Sinha B, Müller RH, Möschwitzer JP. Bottom-up approaches for preparing drug nanocrystals : Formulations and factors affecting particle size. Int J Pharm 2013;453: 126-41.

38. Kesisoglou F, Wu Y. Understanding the Effect of API Properties on Bioavailability Through Absorption Modeling. AAPS J 2008;10(4): 516-25.

39. Ueda K, Iwai T, Sunazuka Y, Chen Z, Kato N, Higashi K. Effect of molecular weight of hypromellose on mucin diffusion and oral absorption behavior of fenofibrate nanocrystal. Int J Pharm 2019;564: 39-47.

40. Guo M, Wei M, Li W, Guo M, Guo C, Ma M, et al. Impacts of particle shapes on the oral delivery of drug nanocrystals : Mucus permeation, transepithelial transport and bioavailability. J Control Release 2019;307: 64-75.

41. Deng $F$, Zhang $H$, Wang $X$, Zhang $Y, H u ~ H$, Song $S$, et al. The transmembrane pathways and mechanisms of rod-like paclitaxel nanocrystals through MDCK polarized monolayer. Appl Mater Interfaces 2017;9(7): 5803-16.

42. Pawar VK, Singh Y, Meher JG, Gupta S, Chourasia MK. Engineered nanocrystal technology : In-vivo fate, targeting and applications in drug delivery. J Control Release 2014;183: 51-66.

43. Fu Q, Sun J, Ai X, Zhang P, Li M, Wang $Y$, et al. Nimodipine nanocrystals for oral bioavailability improvement: Role of mesenteric lymph transport in the oral absorption. Int J Pharm 2013;448: 290-7.

44. Müller RH, Jacobs C. Buparvaquone mucoadhesive nanosuspension : preparation, optimisation and long-term stability. Int J Pharm 2002;237: 151-61.

45. Fu Q, Ma M, Li M, Wang G, Guo M, Li J, et al. Improvement of oral bioavailability for nisoldipine using nanocrystals. Powder Technol 2017;305(103): 757-63. 
46. Lai F, Pini E, Angioni G, Manca ML, Perricci J, Sinico C, Fadda AM. Nanocrystals as tool to improve piroxicam dissolution rate in novel orally disintegrating tablets. Eur J Pharm Biopharm 2011;79: 552-8.

47. Junghanns JAH, Müller RH. Nanocrystal technology, drug delivery and clinical applications. Int J Nanomedicine 2008;3(3): 295-309.

48. Chen M, John M, Lee SL, Tyner KM. Development Considerations for Nanocrystal Drug Products. AAPS J 2017;19(3): 642-51.
49. Basu A, Guti S, Kundu S, Das A, Das S, Mukherjee A. Oral andrographolide nanocrystals protect liver from paracetamol induced injury in mice. J Drug Deliv Sci Technol 2020;55: 101406.

50. Singare DS, Marella S, Gowthamrajan K, Kulkarni GT, Vooturi R, Srinivasa P. Optimization of formulation and process variable of nanosuspension: An industrial perspective. Int J Pharm 2010;402(1-2): 213-20. 